\title{
Clinical and Experimental Pharmacology
}

\section{Individualised Treatment of Alcohol Dependent Patients with Baclofen: A Clinical Observation}

\author{
Martin Becker ${ }^{1 *}$, Lukas Boesch', Markus R Baumgartner ${ }^{2}$, David Johnson ${ }^{3}$ and Rudolf Stohler \\ ${ }^{1}$ Psychiatric University Hospital, Research Group on Substance Use Disorders, Zurich, Switzerland \\ ${ }^{2}$ Institute of Forensic Medicine, University of Zurich, Switzerland
}

${ }^{3}$ NHS Highland, Argyll \& Bute Hospital, Lochgilphead, Argyll, Scotland

*Corresponding author: Martin Becker, Psychiatric University Hospital, Selnaustr. 9, 8001 Zürich, Switzerland, Tel: +41 445558310 ; Fax: +41 44 3171257 ; E-mail: martin.becker@hin.ch

Received: August 15, 2014; Accepted: September 25, 2014; Published: September 30, 2014

Copyright: @ 2014 Becker M, et al. This is an open-access article distributed under the terms of the Creative Commons Attribution License, which permits unrestricted use, distribution, and reproduction in any medium, provided the original author and source are credited.

\section{Abstract}

Objective: The objective of this observational study was to investigate the effectiveness, safety and tolerability of baclofen in individualised doses for the treatment of alcohol dependence in a sample of patients suffering from additional co-occurring mental disorders.

Methods: Fifteen subjects requesting baclofen treatment to achieve abstinence from, or reduction of, alcohol consumption, were included in the study. Baclofen was titrated individually responding to the participants' reports of drug side effects and reductions in drinking and craving. At the start and the end of the observation period (24 weeks) patients self-reported their number of standard drinks per day and rated their alcohol craving by means of the Obsessive Compulsive Drinking Scale (OCD-S). Liver enzymes, Carbohydrate Deficient Transferrin (CDT) and Ethyl Glucuronide in Hair (HEtG) were measured twice.

Results: At the end of the observation period eleven patients were abstinent or low-risk drinking. Mean baclofen dose was $116 \mathrm{mg} / \mathrm{d}$ (range 30-225 mg/d). Baclofen was well tolerated and did not interfere with pre-existing pharmacotherapy. Three patients did not benefit from the treatment. The clinical presentation of one patient improved although his alcohol consumption remained higher than the NIAAA recommendations. We observed indications of baclofen misuse in one patient.

Conclusion: Baclofen treatment with individually titrated doses between $30 \mathrm{mg} / \mathrm{d}$ to $200 \mathrm{mg} / \mathrm{d}$ was associated with suppression of, or reduction in, alcohol consumption and craving in the majority of patients. In view of the small sample size, high motivation of the participants, and absence of a control group we caution against an overestimation of our findings.

Keywords: Alcohol dependence; Individualised titration; GABA B receptor agonist; Baclofen; Clinical observation

\section{Introduction}

In Switzerland, naltrexone, acamprosate and disulfiram are the only medications licensed for the treatment of alcohol dependence but their effect-size is rather small [1-3]

Ethanol affects various biochemical processes such as neurotransmitter release, enzyme function, and ion channel kinetics, but the specific molecular sites to which ethanol molecules bind are still only beginning to be understood [4].

However, GABA mechanisms seem to be important for the motivational effects of alcohol [5]. It was [6] postulated that pre- and postsynaptic GABA B receptors modulate alcohol related reward and reinforcement mechanisms. The activation of these receptors with the GABA B receptor agonist baclofen inhibits dopaminergic neurons indirectly and directly [7]. The importance of the GABA B receptor in the reinforcing and motivational properties of alcohol was confirmed [8].
Preclinical trials [9] demonstrated that baclofen in rodents reduced alcohol consumption and increased abstinence. Further studies [10-13] indicated the effectiveness of baclofen in maintaining abstinence and suppressing craving.

In a double blind, randomised, placebo controlled trial the efficacy and safety of $10 \mathrm{mg}$ baclofen t.i.d. in promoting alcohol abstinence in alcohol dependent patients was shown [14]. Moreover, the safety and efficacy of baclofen (10 mg t.i.d.) in a randomised, double blind controlled trial in a population of alcohol dependent patients with liver cirrhosis was demonstrated [15]. In contrast, no evidence for the efficacy of $10 \mathrm{mg}$ baclofen t.i.d. in the treatment of alcohol dependence was found in another study [16]. In another 12 week trial [17] the efficacy of 30 or $60 \mathrm{mg} / \mathrm{d}$ of baclofen and placebo were compared in a group of alcohol dependent patients. It was demonstrated that even at higher doses baclofen was safe and even more effective in maintaining abstinence and suppressing craving. The safety of higher doses of baclofen $(80 \mathrm{mg})$ in combination with alcohol intoxication was shown [18] in a trial with heavy social drinkers. Two case reports $[19,20]$ showed a total and prolonged suppression of symptoms of alcohol dependence with higher doses of baclofen without severe side effects. An account of four cases treated with baclofen of up to a maximum 
dose of $125 \mathrm{mg} / \mathrm{d}$ either alone, or in combination with acamprosate or naltrexone, was published [21]. In two cases they found prolonged abstinence even after the dosage was reduced to $50 \mathrm{mg} / \mathrm{d}$. Recently, in a sample of 132 participants the safety and efficacy of higher doses of baclofen in maintaining abstinence or lower risk drinking over a period of 12 months was confirmed [22]. Abstinence or reduced consumption in eight of twenty-one patients with psychiatric comorbidities was described in a selected case series [23]. In Switzerland, baclofen as an off-license treatment option for alcohol dependence has received broad publicity, following the German publication of Oliver Ameisen's self-reported cure from severe alcoholism [24].

However, given the partially controversial findings of the hitherto existing studies and the unresolved questions like optimal dosing and potential usefulness in alcohol dependent patients with co-occurring disorders, the aim of our observation was to investigate feasibility, safety and tolerability of individualised doses of baclofen in a sample of alcohol dependent patients with co-occurring mental disorders while retaining the pre-established medication for co-occurring conditions. Moreover, our approach differed from former protocols by including biological markers of alcohol use as an objective outcome measure rather than only relying on self-reported data.

\section{Methods}

Fifteen out-patients participated in the observational study because of their craving for, or consumption of, alcohol. Fourteen out of these fifteen had undergone detoxification treatment in the past and had prior pharmacotherapy for their alcohol dependence without success. All persons asking for the treatment, independent of their aim, (abstinence or reduction in alcohol consumption) were included. Criteria for exclusion were pregnancy, a history of seizure or a psychotic disorder. Consecutively, participants commenced treatment having been informed about the procedure, possible side effects and the off-license nature of the medication. They all signed informed consent.

The ethics commission of the Canton Zürich, Switzerland agreed with the study-procedure.

Before starting treatment (T0) blood samples were taken to determine Mean Cell Volume (MCV), Alanine Aminotransferase (ALAT), Aspartate Aminotransferase (ASAT), Gamma-glutamyltranspeptidase (GGT) and Carbohydrate Deficient Transferrin (CDT).

At this time (T0) we also collected the score of the Obsessive Compulsive Drinking Scale (OCD-S; [25]) and the number of standard drinks/d. The results of the OCD-S were discussed with each participant. All participants attended their weekly Treatment As Usual (TAU) where the individual craving and drinking was discussed. The preexisting pharmacotherapy was continued without significant changes over the course of the observation. Only one woman temporarily reduced her benzodiazepine dosage for two weeks. No patient participated in any other treatment program for alcoholdependence during our study.

Initially the prescribed baclofen dosage was $5 \mathrm{mg}$ t.i.d. and then, after possible side effects (particularly excessive sleepiness) had disappeared, the evening dose was increased to $10 \mathrm{mg}$. In a further stage, first the midday dose and finally the morning dose, was increased. We followed this procedure for each increase in dose. Using this practice we tried to minimise possible side effects. The final dosage was found by considering possible side effects and maximal craving suppression as reported by the participants.

After 24 weeks MCV, ALAT, ASAT, GGT, number of standard drinks/d and the score of the OCD-S were determined again (T2). Ethyl Glucuronide (HEtG), a metabolite of alcohol detectable in hair [26] was analysed by obtaining hair samples cut as close to the scalp as possible at T2. The proximal $3 \mathrm{~cm}$ of hair corresponded to the last 3 months of baclofen treatment assuming a hair growth of $1 \mathrm{~cm} / \mathrm{month}$. Whenever possible we also detected HEtG in the hair $3 \mathrm{~cm}$ to $6 \mathrm{~cm}$ distal from the scalp (T1) covering the first three months of the study. In eleven cases out of fifteen the whole time window of the medication was monitored by hair testing. HEtG in the head hair samples was determined quantitatively with gas chromatography-negative chemical ionisation-tandem mass spectrometry [27]. HEtG values between 7 and $40 \mathrm{pg} / \mathrm{ml}$ (considering the cut-off value $30 \mathrm{pg} / \mathrm{mg}$ with a measurement uncertainty of $\pm 25 \%$ ) correspond with moderate alcohol consumption $[28,29]$.

According to proposed cut-off values [28,29], HEtG values between $7 \mathrm{pg} / \mathrm{ml}$ and $40 \mathrm{pg} / \mathrm{ml}$ (under consideration of the cut-off value of 30 $\mathrm{pg} / \mathrm{mg}$ with the measurement uncertainty of $\pm 25 \%$ ) correspond with moderate alcohol consumption.

Data analysis was done with IBM SPSS Statistics (version 20.0; IBM Corp., Sumers, NY). Intra-individual differences between T0 and T2 were tested using the Wilcoxon signed-rank test. Two-tailed significance-level was set at 0.05 . Due to multiple comparisons, significance-level was adjusted using Bonferroni correction from 0.05 to $0.05 / 8=0.00625$. Differences in HEtG-values are reported without statistical testing, because this variable was not continuous.

\section{Results and Cases}

Preliminarily we describe the cases of an abstinent woman suffering from her craving and of a man who did not benefit from treatment.

\section{Case 4}

A 44-year old woman on a disability pension and a 10 years' history of alcohol dependence attended our outpatient clinic. Over the past ten years she had consumed approximately 16 standard drinks/d and undergone five withdrawal treatments on an inpatient basis. She had been maintained on methadone for the last 15 years because of her heroin dependence and also suffered from a borderline-personality disorder, recurring episodes of depression, an Attention Deficit Hyperactivity Disorder (ADHD), and a Post Traumatic Stress Disorder (PTSD).

After her last withdrawal treatment she requested baclofen medication because of her severe craving. In the past she was prescribed acamprosate and disulfiram, but these drugs had been unsuccessful. We initiated treatment at a dose of $5 \mathrm{mg}$ baclofen t.i.d. When reaching a dosage of $120 \mathrm{mg} / \mathrm{d}$ her craving was totally suppressed. Side effects described by her were weakness and tiredness at the beginning of the treatment and whenever the dosage was increased. These side effects disappeared within three days after stable dosing. All of her blood values, including CDT, were within the normal range.

HEtG was not detectable throughout the observation period. Twenty weeks after the start of the observation baclofen was reduced to $100 \mathrm{mg} / \mathrm{d}$. At T2 there had been no changes in her blood values, but the OCD-S had fallen from 33 at baseline to 8 . 
Page 3 of 6

\section{Case 7}

A 42 year old, unemployed, single man had a history of approximately 8 years of severe drinking (about 20 standard drinks/d). He also suffered from an adult ADHD, a mixed personality disorder with narcissistic, dissocial and emotionally unstable features and recurrent depressive episodes. He smoked cannabis and occasionally consumed cocaine. He had also used Gamma-hydroxybutyrate (GHB) in the past. Inpatient withdrawal treatments had been ineffective in achieving prolonged periods of abstinence and disulfiram-medication had been similarly unsuccessful. When the trial was initiated his depressive disorder was in remission.

At baseline ASAT, ALAT, GGT were slightly raised, CDT was elevated (Table 1) and the OCD-S was 15 . Treatment was started with $5 \mathrm{mg}$ baclofen t.id. During the next meeting he compared the effects of baclofen to those of GHB. Gradually we increased the dosage to 150 $\mathrm{mg} / \mathrm{d}$. The patient described a reduction in craving, but was not totally satisfied with the effect. Without consulting his physician, he increased the dosage form $150 \mathrm{mg} / \mathrm{d}$ to $200 \mathrm{mg} / \mathrm{d}$ over three days. However, tiredness and dizziness were the only side effects he described. Moreover, he reported that his craving was minimised. Although the patient reported a reduction of his craving and drinking, we measured a CDT value of $7.6 \%$ at the end of the investigation. ASAT, ALAT and GGT values also remained elevated. HEtG was raised to $320 \mathrm{pg} / \mathrm{mg}$ during the last three months of the trial.

When shown these results, the patient disclosed that his alcohol consumption had been unaffected by baclofen, but stated that he felt more relaxed and more self-confident when taking the medication. Although his alcohol consumption had increased he requested continuation of the treatment but agreed to a dosage reduction to 150 $\mathrm{mg} / \mathrm{d}$. We cannot exclude the possibility that he found other sources to purchase baclofen.

All participants, ten Caucasian men and five women, median age 40 years, range 32 to 60 years, completed the observation. Two women were abstinent when the observation started and no withdrawal management was necessary in any participants. The duration of alcohol dependence ranged from 2 to 28 years with a median duration of 10 years. One male participant did not suffer from co-occurring mental disorders. Three participants (one female and two males) occasionally took disulfiram or clomethiazol.

At the end of the observation the individual baclofen dosages ranged between $30 \mathrm{mg}$ and $225 \mathrm{mg} / \mathrm{d}$. Mean baclofen dose was 116 $\mathrm{mg} / \mathrm{d}$, while median dosage was $100 \mathrm{mg} / \mathrm{d}$. Ten participants used doses between $75 \mathrm{mg} / \mathrm{d}$ and $125 \mathrm{mg} / \mathrm{d}$, three men had dosages between 200 $\mathrm{mg} / \mathrm{d}$ and $225 \mathrm{mg} / \mathrm{d}$, one woman used $30 \mathrm{mg} / \mathrm{d}$ and an additional 10 $\mathrm{mg}$ in risky situations. One woman was treated with a dosage of 60 $\mathrm{mg} / \mathrm{d}$.

The following, temporary Adverse Effects (AEs) were experienced (frequency in parentheses): tiredness, drowsiness or sedation (14), dizziness (4), headache (3), nausea (3), muscle weakness (1), visual disturbances (1), back pain (1) and erectile dysfunction (1). No individual withdrew from the observation because of AEs. These AEs appeared to be in response to increases in dose and would resolve within three to five days. One person experienced no side effects. A potential Serious Adverse Event (SAE) was observed in one participant where there were indications of misuse (see Case 7 and Discussion).

According to ICD-10 diagnostic criteria co-occurring mental health disorders (incidence in parentheses) were: depressive episodes (12), cocaine dependence or misuse (7), opioid dependence (4), personality disorders (4), attention deficit hyperactivity disorders (4), anxiety disorders (2), post-traumatic stress disorders (1) and eating disorders (1). Fourteen patients suffered from concomitant mental disorders and five patients were diagnosed with four or more mental disorders. One man had no co-occurring mental disorder. Medications prescribed along with baclofen (incidence in parentheses) were: antidepressants (14), benzodiazepines (7), methadone or buprenorphine (4), methylphenidate (4), mood stabilisers (2) and antipsychotics (2).

At the end of the observation we found no statistically significant reductions in CDT, MCV, ASAT, ALAT and GGT in 13 patients (Table 1 and Table 2).

\begin{tabular}{|c|c|c|c|c|c|c|c|c|c|c|c|c|c|}
\hline \multirow[t]{2}{*}{ Patient No. } & \multirow[t]{2}{*}{ Gender } & \multirow[t]{2}{*}{ Age [y] } & \multicolumn{2}{|c|}{$\operatorname{MCV}[f]]$} & \multicolumn{2}{|c|}{ ASAT [U/l] } & \multicolumn{2}{|c|}{ ALAT [U//] } & \multicolumn{2}{|c|}{ GGT [U/l] } & \multicolumn{2}{|c|}{ CDT [\%] } & \multirow[t]{2}{*}{ Baclofen $[\mathrm{mg} / \mathrm{d}]$} \\
\hline & & & T0 & T2 & T0 & $\mathrm{T} 2$ & T0 & T2 & T0 & T2 & TO & $\mathrm{T} 2$ & \\
\hline 1 & $\mathrm{~m}$ & 35 & 94.0 & 92.0 & 11.0 & 17.0 & 12.0 & 11.0 & 81.0 & 11.0 & 1.8 & 1.5 & 105.00 \\
\hline 2 & $f$ & 58 & 94.0 & 90.0 & 17.0 & 18.0 & 18.0 & 22.0 & 46.0 & 6.0 & 2.5 & 1.6 & 75.00 \\
\hline 3 & $f$ & 34 & - & - & 17.0 & 21.0 & 21.0 & 19.0 & 17.0 & 17.0 & 1.8 & 1.7 & 75.00 \\
\hline 4 & $f$ & 44 & 88.0 & 84.0 & 15.0 & 16.0 & 20.0 & 17.0 & 24.0 & 27.0 & 1.5 & 1.7 & 100.00 \\
\hline 5 & $f$ & 66 & 86.0 & 84.0 & 57.0 & 16.0 & - & 18.0 & - & 18.0 & - & 1.8 & 30.00 \\
\hline 6 & $\mathrm{~m}$ & 50 & - & 92.0 & 71.0 & 19.0 & 98.0 & 18.0 & 109.0 & 22.0 & - & 2.4 & 125.00 \\
\hline 7 & $\mathrm{~m}$ & 42 & 95.0 & 95.0 & 27.0 & 36.0 & 36.0 & 36.0 & 67.0 & 51.0 & 4.7 & 7.6 & 200.00 \\
\hline 8 & $\mathrm{~m}$ & 40 & 89.0 & 90.0 & 25.0 & 29.0 & 21.0 & 26.0 & 60.0 & 53.0 & - & 2.8 & 125.00 \\
\hline 9 & $\mathrm{~m}$ & 38 & 102.0 & 103.0 & 21.0 & 30.0 & 44.0 & 49.0 & 185.0 & 274.0 & 2.1 & 1.7 & 200.00 \\
\hline 10 & $m$ & 46 & - & - & 19.0 & 23.0 & 29.0 & 64.0 & 18.0 & 50.0 & 1.7 & 2.1 & 125.00 \\
\hline 11 & $f$ & 46 & 99.0 & 96.0 & 27.0 & 33.0 & 24.0 & 28.0 & 23.0 & 11.0 & 9.4 & 2.7 & 60.00 \\
\hline
\end{tabular}


Citation: Becker M, Boesch L, Baumgartner MR, Johnson D, Stohler R (2014) Individualised Treatment of Alcohol Dependent Patients with

\begin{tabular}{|l|l|l|l|l|l|l|l|l|l|l|l|l|l|}
\hline 12 & $\mathrm{~m}$ & 32 & 91.0 & 91.0 & 32.0 & 37.0 & 78.0 & 58.0 & 72.0 & 73.0 & 1.8 & 1.5 & 85.00 \\
\hline 13 & $\mathrm{~m}$ & 38 & 100.0 & 94.0 & 29.0 & 26.0 & 47.0 & 45.0 & 160.0 & 111.0 & - & 2.2 & 100.00 \\
\hline 14 & $\mathrm{~m}$ & 30 & 99.0 & 91.0 & 16.0 & 33.0 & 17.0 & 18.0 & - & 16.0 & 1.8 & - & 75.00 \\
\hline 15 & $\mathrm{~m}$ & 38 & - & - & 92.0 & 65.0 & 56.0 & 52.0 & 370.0 & 76.0 & 2.2 & 1.8 & 225.00 \\
\hline $\mathrm{M}$ & - & 42.40 & 94.27 & $91.83^{*}$ & 31.73 & 27.93 & 37.21 & 32.06 & 94.76 & 54.40 & 2.84 & 2.36 & 115.66 \\
\hline SD & - & 6.66 & 5.33 & 5.11 & 23.26 & 12.64 & 25.31 & 17.21 & 98.11 & 67.81 & 2.34 & 1.56 & 55.19 \\
\hline
\end{tabular}

Table 1: Blood testing results. T0: beginning of the observation; T2: end of the observation; -: missing value; ${ }^{*} \mathrm{p}<0.01$

A statistically significant decrease was detected in mean OCD-S total score from $\mathrm{T} 0(20.15 ; \mathrm{SD}=7.28)$ to $\mathrm{T} 2(8.07 ; \mathrm{SD}=4.87$; Wilcoxon
$\mathrm{Z}=-3.06 ; \mathrm{p}=0.002$ ), and self-reported standard drinks/d (from $12.91 \pm$ 6.46 to $2.84 \pm 6.99$, Wilcoxon: $Z=-2.83 ; \mathrm{p}=0.005$ ) (Table 2 ).

\begin{tabular}{|c|c|c|c|c|c|c|c|c|}
\hline \multirow[t]{2}{*}{ Patient No. } & \multicolumn{2}{|c|}{ OCD-S } & \multicolumn{2}{|c|}{ St. dr./d } & \multicolumn{2}{|c|}{ HEtG [pg/mg] } & \multirow{2}{*}{$\begin{array}{l}\text { Baclofen } \\
\text { dosage }[\mathrm{mg} / \mathrm{d}]\end{array}$} & \multirow{2}{*}{$\begin{array}{l}\text { Duration of } \\
\text { dependence }[y]\end{array}$} \\
\hline & T0 & T2 & T0 & T2 & T1 & $\mathrm{T} 2$ & & \\
\hline 1 & 26 & 1 & 14.50 & 1.00 & 11 & 9 & 105.00 & 7.00 \\
\hline 2 & 10 & 2 & 9.50 & 0.10 & $<7$ & $<7$ & 75.00 & 16.00 \\
\hline 3 & 20 & 8 & 5.00 & 1.50 & - & - & 75.00 & 10.00 \\
\hline 4 & 33 & 8 & 16.10 & 0 & 0 & 0 & 100.00 & 10.00 \\
\hline 5 & 15 & 9 & 5.10 & 0 & 8 & $<7$ & 30.00 & 2.00 \\
\hline 6 & 27 & 10 & 19.10 & 1.50 & - & 46 & 125.00 & 2.00 \\
\hline 7 & 15 & - & 19.70 & 26.00 & - & 320 & 200.00 & 8.00 \\
\hline 8 & 20 & 13 & 16.00 & 2.50 & 8 & 17 & 125.00 & 7.00 \\
\hline 9 & 30 & - & - & - & 23 & 62 & 200.00 & 15.00 \\
\hline 10 & 20 & 8 & 0 & 1.00 & - & 18 & 125.00 & 27.00 \\
\hline 11 & 30 & 18 & 15.80 & 0.50 & 8 & 9 & 60.00 & 28.00 \\
\hline 12 & 19 & 4 & 16.00 & 1.00 & $<7$ & $<7$ & 85.00 & 2.00 \\
\hline 13 & 14 & 14 & 10.00 & - & 70 & 180 & 100.00 & 13.00 \\
\hline 14 & 9 & 5 & 10.00 & 0.70 & 19 & 22 & 75.00 & 14.00 \\
\hline 15 & 19 & 5 & 21.10 & 1.20 & 34 & 28 & 225.00 & 15.00 \\
\hline M & 20.15 & $8.07^{*}$ & 12.91 & $2.84^{*}$ & - & - & 115.66 & 11.73 \\
\hline SD & 7.28 & 4.87 & 6.46 & 6.99 & - & - & 55.19 & 7.98 \\
\hline
\end{tabular}

Table 2: OCD-S, standard drink/d, HEtG, baclofen dosage and duration of dependence in years. T0: beginning of the observation; T1: after 12 weeks; T2: end of the observation; -: missing value; ${ }^{*} \mathrm{p}<0.01$

The individual results are shown in Tables 1 and 2.

In conclusion, four patients (three women and one man) achieved abstinence and six reduced their consumption to a low or moderate level. One female participant (case 3 ) described a reduction in craving. Unfortunately she had bleached her hair so HEtG was not quantifiable although her clinical presentation supported her statement. Patient six stated that he was able to reduce his alcohol consumption although the HEtG value of $46 \mathrm{pg} / \mathrm{mg}$ remained elevated.

Three male participants did not benefit from the treatment. 


\section{Discussion}

The heterogeneity of the sample was not only due to differing cooccurring mental disorders but also differing starting conditions, duration of dependence and differing ambitions of the participants. The majority of the participants intended to reduce their drinking to a non-problematic level. Fourteen of fifteen participants in our observation had co-occurring mental disorders and were prescribed concomitant psychotropic medication. Baclofen seemed not to interfere with the other psychotropic drugs and was well tolerated by all participants. Transient side effects had no influence on treatment adherence. Over the course of the observation no participant dropped out. The individualised titration of baclofen following the needs, requests and mental states of each participant might have contributed to these findings.

In total we saw an improvement of 12 participants. Two women were abstinent when the observation began and remained abstinent. Two persons, who were dependently drinking at T0 also achieved abstinence. Six participants reduced their alcohol consumption. Their self-declared consumption at the end of the observation of less than 2.5 standard drinks/d corresponded with the maximum HEtG value of $28 \mathrm{pg} / \mathrm{mg}$. Two of these six patients achieved HEtG values below 10 $\mathrm{pg} / \mathrm{mg}$. Their consumption was compatible with low risk drinking according to the recommendations of NIAAA [30]. The self-reported reduction in alcohol consumption in those patients who were compliant with treatment was consistent with their HEtG-levels. The statements of drinking and craving of cases three and six could not be confirmed by their HEtG values even though their clinical presentation improved.

Alcohol consumption of three males increased under high and the highest dosages of baclofen, according to their HEtG levels. However, adherence to treatment of these men was presumably poor. During the observation all three reported a reduction in the number of standard drinks/d. When shown the results of their HEtG levels they disclosed that their declarations had been inaccurate. Two of these individuals agreed to a gradual tapering and discontinuation of baclofen which occurred over several weeks. No additional medication was necessary and no harm was reported during this period. Only case 7 requested continuation of baclofen because he thought he had benefited from the treatment by an increased self-confidence and a more relaxed demeanour. Our experience with this case over the course of the observation has led us to conclude that baclofen has a potential of misuse. Therefore we advise caution in cases with poor therapy adherence, high dosage of baclofen and a repeated request for dosage increase.

Measures to optimise treatment adherence would be a useful strategy for clinicians in cases where there might be a potential for misuse to prevent overdosing (accidental or non-accidental) along with daily administration of medication.

In total, craving reduction or suppression was achieved with a maximum baclofen dosage of $100 \mathrm{mg} / \mathrm{d}$ for all five women and with a maximum of $225 \mathrm{mg} / \mathrm{d}$ for seven men. This may suggest that women experience reduced cravings with a lower dose when compared to men.

The age of participants and the duration of dependence did not influence the efficacy of treatment. Mean baclofen dose was $116 \mathrm{mg} / \mathrm{d}$.

This clinical observation study is limited by the small sample size and its design as a clinical observation. In our small observation females improved more than males at lower dosages. Further studies are necessary to corroborate this finding. Thirteen participants asked for continuation of treatment, after the 24 week observation period. Eight months after the end of the observation, ten of the participants were stable in abstinence or low risk drinking.

The self-declared number of standard drinks/d before the observation could not be confirmed by HEtG values. This is a second limitation, because it is possible that participants consumed initially more or less alcohol than their declared amount. However, at T1 ten participants' HEtG results were below $40 \mathrm{pg} / \mathrm{mg}$ and these results remained stable or even decreased till $\mathrm{T} 2$. This may indicate the prolonged effect of the treatment.

Absence of any blood-levels of baclofen is a third limitation and we have been unable to find a correlation between the prescribed dosages and the reduction or suppression of craving for, and drinking of, alcohol in our sample. Recently, a study showed a proportional relationship between baclofen dose and exposure but also observed that similar doses did not lead to similar exposure [31]. Because of the wide inter-individual variability further studies are necessary to elucidate the association of clinical efficacy and baclofen exposure.

The effect of baclofen in suppressing dependent alcohol consumption is questionable in the two females who were abstinent at the beginning of our observation. However, both reported a suppressed craving while on baclofen and remain abstinent.

The outcome of our observation might have been confounded by three participants occasionally taking disulfiram or clomethiazol medication. These medications were not taken regularly by any of these participants but we cannot exclude this intake influencing the results.

Moreover, when interpreting our findings, it should be born in mind that the patients involved in this observation study had specifically requested baclofen treatment as they had been convinced of baclofen's effectiveness. Beliefs of participants may have an important impact on the outcome of a trial [32]. Nevertheless the results of our study are comparable to previous findings in which patients were not reported to be specifically biased in favour of baclofen.

\section{Conclusion}

In our heterogeneous sample also treated with other psychotropic medications the majority of participants benefited from the individual titration of baclofen. In three participants we noticed a decline in their condition. Baclofen might have a risk of misuse.

\section{Declaration of Interest}

The authors report no conflicts of interest. The authors alone are responsible for the content and writing of the paper.

\section{Acknowledgement}

We are grateful to Dr. Ameisen for his support and sharing of experience. We thank all patients who agreed to participate in this observation. 


\section{References}

1. Mann K, Lehert P, Morgan MY (2004) The efficacy of acamprosate in the maintenance of abstinence in alcohol-dependent individuals: results of a meta-analysis. See comment in PubMed Commons below Alcohol Clin Exp Res 28: 51-63.

2. Rössner A, Hackl-Herrwerth A, Leucht S, Vecchi S, Srisurapanot M, et al. (2005) Opioid antagonists for alcohol dependence. Cochrane Database of Systematic Reviews 1, CD 001867.

3. Fuller RK, Branchey L, Brightwell DR, Derman RM, Emrick CD, et al. (1986) Disulfiram treatment of alcoholism. A Veterans Administration cooperative study. See comment in PubMed Commons below JAMA 256: 1449-1455.

4. Harris RA, Trudell JR, Mihic SJ (2008) Ethanol's molecular targets. See comment in PubMed Commons below Sci Signal 1: re7.

5. Koob GF (2004) A role for GABA mechanisms in the motivational effects of alcohol. See comment in PubMed Commons below Biochem Pharmacol 68: 1515-1525.

6. Ariwodola OJ, Weiner JL (2004) Ethanol potentiation of GABAergic synaptic transmission may be self-limiting: role of presynaptic GABA(B) receptors. See comment in PubMed Commons below J Neurosci 24: 10679-10686.

7. Westerink BH, Kwint HF, deVries JB (1996) The pharmacology of mesolimbic dopamine neurons: a dual-probe microdialysis study in the ventral tegmental area and nucleus accumbens of the rat brain. See comment in PubMed Commons below J Neurosci 16: 2605-2611.

8. Maccioni P, Zaru A, Loi B, Lobiana C, Carai MAM, et al. (2012) Comparison of the Effect of GABA B Receptor Agonist, Baclofen, and the Positive Allosteric Modulator of the GABA B Receptor, GS39783, on Alcohol Self-Administration in 3 Different Lines of Alcohol-Prefering Rats. Alcohol Clinic Exp Res 36: 1748-1766.

9. Colombo G, Serra S, Brunetti G, Vacca G, Carai MA, et al. (2003) Suppression by baclofen of alcohol deprivation effect in Sardinian alcohol-preferring (sP) rats. See comment in PubMed Commons below Drug Alcohol Depend 70: 105-108.

10. Addolorato G, Leggio L, Abenavoli L, Agabio R, Caputo F, et al. (2006) Baclofen in the treatment of alcohol withdrawal syndrome: a comparative study vs diazepam. See comment in PubMed Commons below Am J Med 119: 276.

11. Leggio L, Garbutt JC, Addolorato G (2010) Effectiveness and safety of baclofen in the treatment of alcohol dependent patients. See comment in PubMed Commons below CNS Neurol Disord Drug Targets 9: 33-44.

12. Johnson BA, Swift RM, Addolorato G, Ciraulo DA, Myrick H (2005) Safety and efficacy of GABAergic medications for treating alcoholism. See comment in PubMed Commons below Alcohol Clin Exp Res 29: 248-254.

13. De Beaurepaire R (2012) Suppression of alcohol dependence using baclofen: a 2-year observational study of 100 patients. Front Psychiatry 3: 1-7.

14. Addolorato G, Caputo F, Capristo E, Domenicali M, Bernardi M, et al. (2002) Baclofen efficacy in reducing alcohol craving and intake: a preliminary double-blind randomised controlled study. Alcohol Alcohol 37: 504-508

15. Addolorato G, Leggio L, Ferrulli A, Cardone S, Bedogni G, et al. (2007) Effectiveness and safety of baclofen for maintenance of alcohol abstinence in alcohol-dependent patients with liver cirrhosis: randomized, double blind controlled study. Lancet 370: 1915-1922.

16. Garbutt JC, Kampov-Polevoy AB, Gallop R, Kalka-Juhl L, Flannery BA (2010) Efficacy and safety of baclofen for alcohol dependence: a randomized, double blind, placebo-controlled trial. Alcohol Clin Exp Res 34: 1849-1857.

17. Addolorato G, Leggio L, Ferrulli A, Cardone S, Bedogni G, et al. (2011) Dose-response effect of baclofen in reducing daily alcohol intake in alcohol dependence: secondary analysis of a randomized, double-blind, placebo-controlled trial. Alcohol Alcohol 46: 312-317.

18. Evans SM, Bisaga A (2009) Acute interaction of baclofen in combination with alcohol in heavy social drinkers. Alcohol Clin Exp Res 33: 19-30.

19. Ameisen O (2005) Complete and prolonged suppression of symptoms and consequences of alcohol dependence using high-dose baclofen: a self-case report of a physician. Alcohol Alcohol 40: 147-150.

20. Bucknam W (2007) Suppression of symptoms of alcohol dependence and craving using high dose baclofen. Alcohol Alcohol 42: 158-160.

21. Pastor A, Jones DML, Currie J (2012) High-dose baclofen for treatmentresistant alcohol dependence. J Clin Psychopharmacol 32: 266-268.

22. Rigal L, Alexandre-Dubroeucq C, deBeaurepaire R, Le Jeunne C, Jaury P (2012) Abstinence and 'low risk' consumption 1 year after the initiation of high-dose baclofen: a retrospective study among 'high-risk' drinkers. Alcohol Alcohol 47: 433-442.

23. Dore GM, Lo K, Juckes L, Bezyan S, Latt N (2011) Clinical experience with baclofen in the management of alcohol-dependent patients with psychiatric comorbidity: a selected case series. Alcohol Alcohol 46: 714720

24. Ameisen O (2009) Das Ende meiner Sucht, Verlag Antje Kunstmann, München.

25. Mann K, Ackermann K (2000) Die OCDS-G: Psychometrische Kennwerte der deutschen Version der Obsessive Compulsive Drinking Scale. Sucht 46: 90-100.

26. Morini L, Polit L, Poletti A (2009) Ethy glucuronide in hair. A sensitive and specific marker of chronic heavy drinking. Addiction 104: 915- 920.

27. Yegles M, Panarotto E, Labarthe A, Wennig R (2001) Determination by GC-MS/NCI of ethyl glucuronide in hair. In: Pragst F, Aderjan R (Eds), Beiträge zum XII. Symposium der GTFCh, Mosbach/Baden, Verlag Dr. Dieter Helm, 299-303.

28. Kintz P (2011) Cosensus of the Society of Hair Testing on hair testing for chronic excessive alcohol consumption 2011. Forensic Science International 218: 2.

29. Society of Hair Testing (2012) Use of Alcohol Markers in Hair for Abstinence Assessment.

30. NIAAA (2012) Alcohol \& Your Health. National Institute on Alcohol Abuse and Alcoholism of the National Institute of Health, Bethesda.

31. Marsot A, Imbert B, Alvarez J-C, Grassin-Delyle S, Jaquet I, et al. (2014) High Variability in the Exposure of Baclofen in Alcohol-Dependent Patients, Alcohol Clin Exp Res 38: 316-321.

32. Colagiuri B, Morley K, Boakes R, Haber P (2009) Expectancy in DoubleBlind Placebo-Controlled Trials: An Example from Alcohol Dependence. Psychother Psychosom 78: 167-171. 